This item was submitted to Loughborough's Research Repository by the author.

Items in Figshare are protected by copyright, with all rights reserved, unless otherwise indicated.

\title{
Geometry optimization of linear and annular plasma synthetic jet actuators
}

PLEASE CITE THE PUBLISHED VERSION

http://dx.doi.org/10.1088/1361-6463/50/1/015210

PUBLISHER

IOP Publishing

VERSION

AM (Accepted Manuscript)

LICENCE

CC BY-NC-ND 4.0

REPOSITORY RECORD

Neretti, Gabriele, Paolo Seri, Matteo Taglioli, Alexander H. Shaw, Felipe Iza, and Carlo A. Borghi. 2019. "Geometry Optimization of Linear and Annular Plasma Synthetic Jet Actuators". figshare.

https://hdl.handle.net/2134/22791. 


\title{
Geometry Optimization of Linear and Annular Plasma Synthetic Jet Actuators
}

\author{
G. Neretti ${ }^{1}$, P. Seri ${ }^{1}$, M. Taglioli $^{1}$, A. Shaw ${ }^{2}$, F. Iza ${ }^{2}$ and C. A. Borghi ${ }^{1}$ \\ ${ }^{1}$ Department of Electric, Electronic and Information Engineering, University of Bologna, Bologna, 40136 \\ Italy \\ ${ }^{2}$ Wolfson School of Mechanical, Electrical and Manufacturing Engineering, Loughborough University, \\ Loughborough, LE11 3TU, UK \\ e-mail: gabriele.neretti@unibo.it
}

\section{ABSTRACT}

The Electro-Hydro-Dynamic (EHD) interaction induced in atmospheric-pressure air by a surface Dielectric Barrier Discharge (DBD) actuator has been experimentally investigated. Plasma Synthetic Jets Actuators (PSJAs) are DBD actuators able to induce an air stream, perpendicular to the actuator surface. These devices can be used in the aerodynamics field to prevent or induce flow separation, modify the laminar to turbulent transition inside the boundary layer, and stabilize or mix air flows. They can also be used to enhance indirect plasma treatment effects, increasing the reactive species delivery rate onto surfaces and liquids. This can play a major role in plasma processing and chemical kinetics modelling, where only diffusive mechanisms are often considered.

This paper reports on the importance that different electrode geometries can have on the performance of different PSJAs. A series of DBD aerodynamic actuators designed to produce perpendicular jets have been fabricated on 2-layer printed circuit boards (PCBs). Linear and annular geometries have been considered, testing different upper electrode distances in the linear case and different diameters in the annular one. AC voltage supplied at $11.5 \mathrm{kV}$ peak and $5 \mathrm{kHz}$ frequency has been used. Lower electrodes were connected to ground and buried in epoxy resin to avoid undesired plasma generation on the lower actuator surface.

Voltage and current measurements have been carried out to evaluate the active power delivered to the discharges. Schlieren imaging allowed to visualize the induced jets and gave an estimate of their evolution and geometry. Pitot tube measurements were performed to obtain the PSJAs' velocity profiles and to estimate the mechanical power delivered to the fluid.

Optimal values of the inter-electrode distance and diameter have been found in order to maximize jet velocity, mechanical power or efficiency. Annular geometries are found to achieve the best performances.

Keywords: Non thermal plasma, Dielectric barrier discharge, Electro hydro dynamics, Plasma actuators geometry, DBD, EHD

\section{INTRODUCTION}

In the last twenty years, the field of active flow control has been growing considerably [1]. An efficient active flow control system can prevent or induce flow separation, modify the laminar to turbulent transition inside the boundary layer, and stabilize or mix air flows in order to avoid unwanted vibrations, noise, and energy losses. Moreover, it can reduce the drag and enhance the lift of a wing [2].

EHD interaction is produced by a non-thermal plasma layer generated by a Dielectric Barrier Discharge (DBD); this effect is also called ionic wind. This ionic wind can significantly modify the properties of the 
boundary layer developing on body surfaces [3]. Interest for this phenomenon is growing in aeronautics, astronautics [4-20], and for turbine blade applications [21-25]. Plasma aerodynamic actuators are more attractive than other active actuator technologies because they feature high dynamic responses due to the absence of moving parts and low weight, they are easy to build, backward compatible with existing aerodynamic surfaces, and generate negligible aerodynamics interferences when not in use.

The EHD effect can also be used to generate convective flows. Such a feature can be exploited to enhance indirect plasma treatments, increasing the delivery of plasma reactive species onto surfaces or liquids, thereby increasing their efficacy (sterilization, ozonisation, surface treatments, etc.) $[26,27]$.

A DBD aerodynamic plasma actuator can be constituted by a dissymmetric electrode pair separated by a dielectric slab (Fig. 1). When high voltages (typically $10-50 \mathrm{kV}$ at $1-100 \mathrm{kHz}$ ) are applied to the electrodes, a surface discharge is produced. Due to the asymmetric electrode arrangement, a suction region is generated above the exposed electrode [28]. Air enters this depression region and experiences a unidirectional thrust tangentially to the actuator surface. The discharge appears to be macroscopically homogeneous to the unaided eye, but it is constituted by a sequence of micro-discharges lasting typically for tens of nanoseconds, with a repetition rate of several hundreds of $\mathrm{MHz}$ [3]. The discharge dynamics can be inferred by voltage-current time behaviour reported in Fig. 2 .

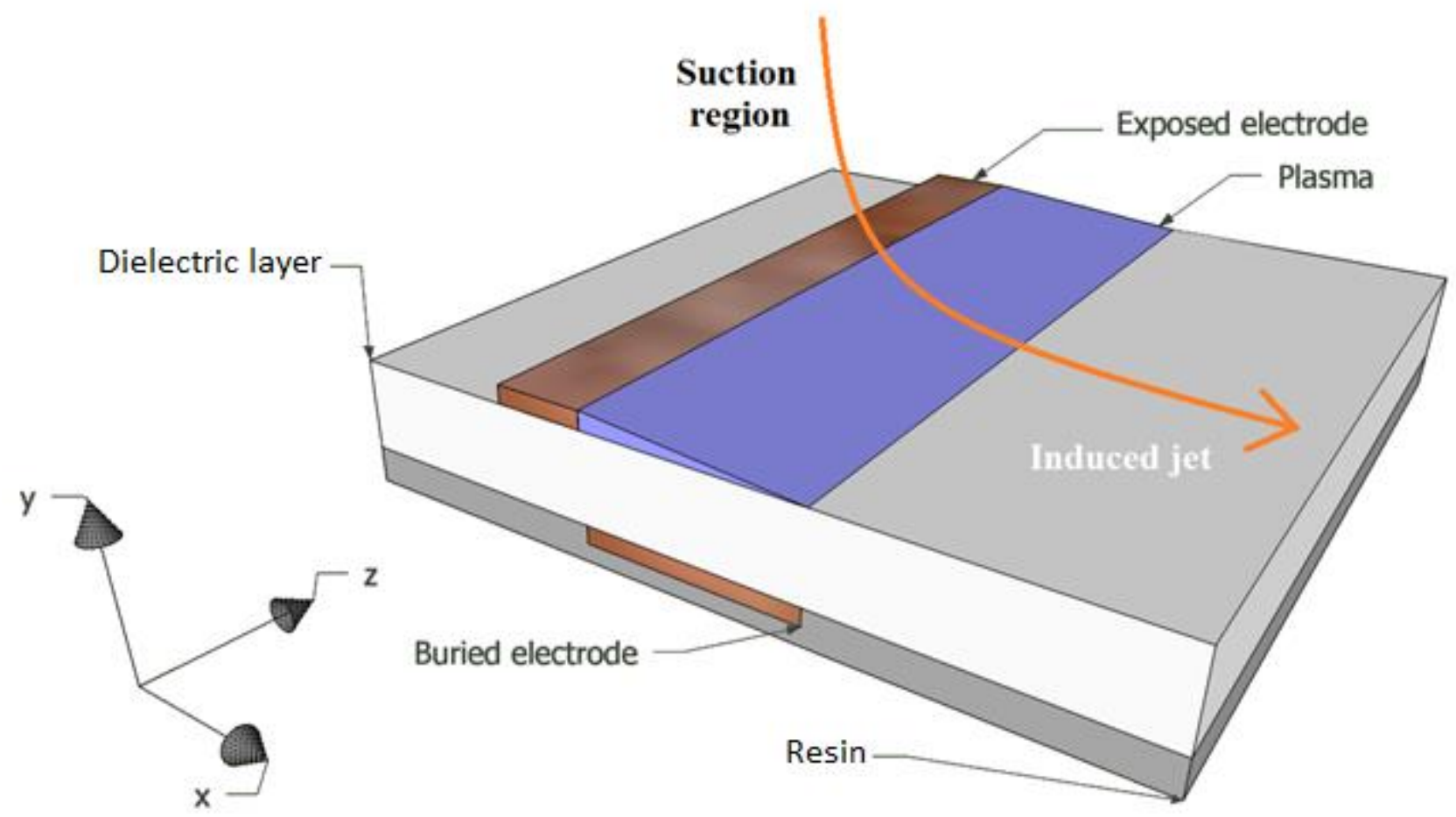

Fig. 1-A DBD aerodynamic plasma actuator constituted by a dissymmetric electrode pair separated by a dielectric layer. 


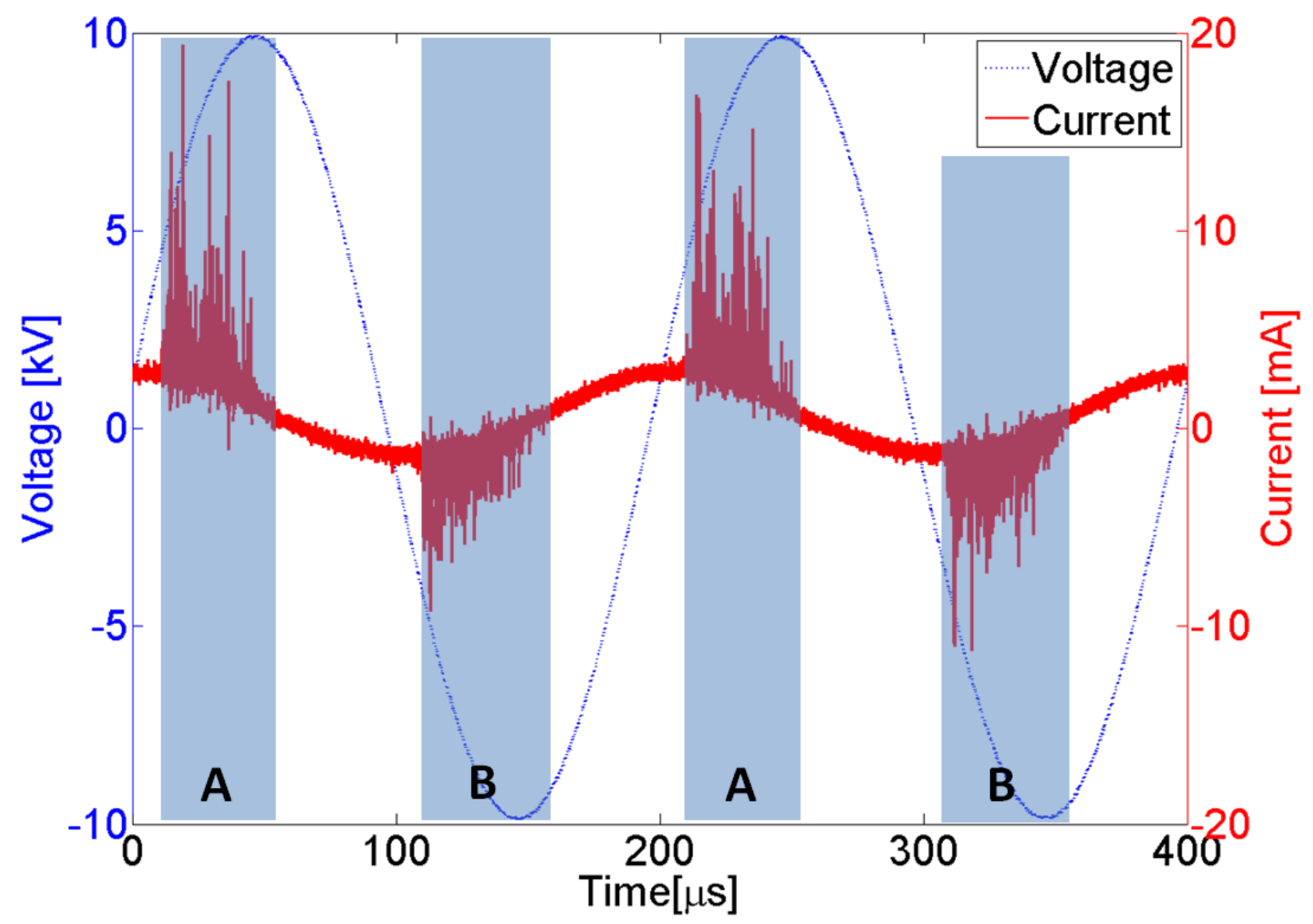

Fig. 2 - Voltage and current time behaviours. Plasma is ignited during the highlighted time intervals.

Plasma is ignited during the time intervals in which the absolute value of the voltage increases (time intervals A and B highlighted in Fig. 2). Each current pulse is formed by assembly sequence of streamers that are thin filaments, with a diameter of $10-100 \mu \mathrm{m}[29,30]$.

The presence of plasma and the particular electrode configuration induce a jet tangential to the actuator wall [3]. A so-called vectorized jet, perpendicular to the actuator surface, can be produced by two tangential jets acting in opposite directions, colliding with each other (Fig. 3). The easiest system achieving such effect provides two linear couples of electrodes, in a symmetrical layout [31-34]. 


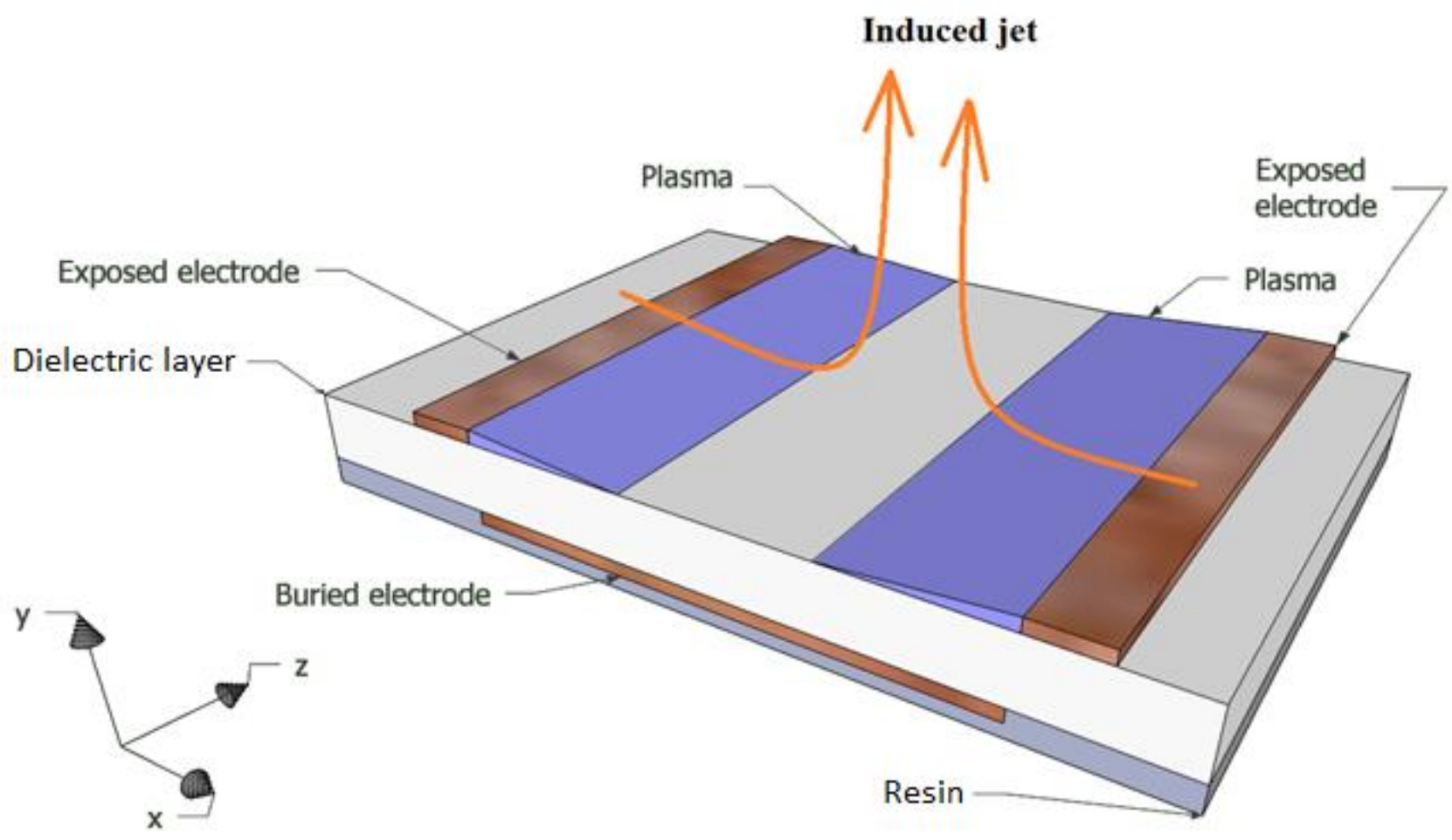

Fig. 3 - A perpendicular vectorized jet produced by two DBD actuators acting in opposite directions.

Previous works have established that DBD plasma actuators can influence the fluid dynamics of an airfoil for traveling speeds up to $20 \mathrm{~m} / \mathrm{s}$ [34-36]. Such relatively low speed limit is a typical restriction characterizing such plasma actuators.

Part of the reason behind this restricting factor is the top speed of the ionic wind. The wind speed is limited by the highest intensity of the electric field generated in the actuator; higher fields can damage the dielectric layer and/or progressively change the plasma morphology. With higher voltages and higher electric fields, a less diffused morphology of the discharge, with stronger and longer streamers, may be originated. Such inhomogeneous plasma is less efficient from the EHD effect point of view [2]. Other known parameters are able to increase the ionic wind speed which include the dielectric layer properties and the waveform of the voltage feeding the electrodes [37-46].

Another factor influencing the EHD effect is geometry [39,41]. This study will focus on the importance that different actuator geometries can have on the EHD effect. Linear and annular electrodes (Fig. 4) with different electrode distances and diameters have been studied. Electrodynamic and fluid dynamic measurements have been performed to characterize the plasma and the EHD effect intensity. Optimal values of the inter-electrode distance in linear devices and the diameter in annular devices have been found in order to maximise the jet's velocity, mechanical power and efficiency. 


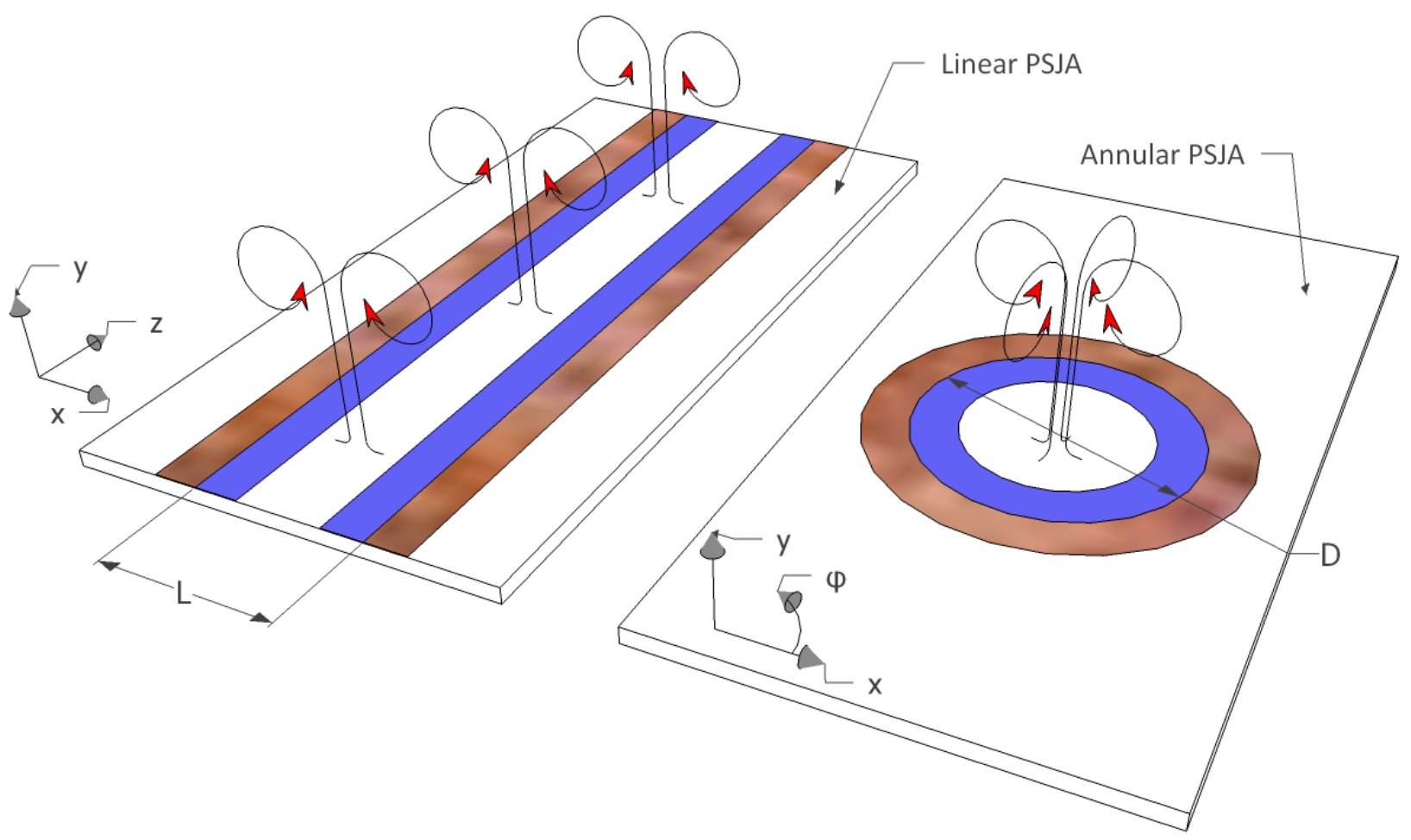

Fig. 4 - Tested geometries: linear (left) and annular (right).

\section{EXPERIMENTAL SETUP}

A series of DBD aerodynamic actuators, producing jets perpendicularly to the actuator surface, have been fabricated on 2-layer PCBs, with $35 \mu \mathrm{m}$ thick copper electrodes and $1.5 \mathrm{~mm}$ thick glass epoxy (FR-4) as dielectric. Linear and annular geometries have been used. In the linear case two linear high voltage upper electrodes parallel to each other were used in order to generate a perpendicular jet. The annular ones are axisymmetric. In this case one high voltage upper electrode produces the perpendicular jet. Annular and linear layouts share the same cross section. Those two configurations layouts are shown in Fig. 4. Electrode width has been fixed to $5 \mathrm{~mm}$. In the linear case the length of the electrodes along the $z$-axis is $50 \mathrm{~mm}$. This work studies actuators with upper electrode gaps in the linear case ( $\mathrm{L}$ in Fig. 4 ) and electrode diameters in the circular case (D in Fig. 4) of 10, 14, 18, 22, 26, 30, 34, 38, 42, 46, and $50 \mathrm{~mm}$.

Experiments were performed in still air at atmospheric pressure. The power supply feeding the actuator was constituted by a signal generator, an amplifier, and a transformer, as shown in [47]. An HP-Agilent 33120-A signal generator produced a low voltage (2-4 V) AC signal with a frequency of $5 \mathrm{kHz}$ that was delivered to an Elgar Model $3001 \mathrm{AC}$ amplifier. A high voltage ferrite transformer was used to increase the voltage to the desired value of $11.5 \mathrm{kV}_{\mathrm{p}}$.

Voltage and current applied to the electrodes have been measured by means of two probes connected to a Yokogawa DL1740 4-channel, $500 \mathrm{MHz}$ bandwidth, $1 \mathrm{GS} / \mathrm{s}$ oscilloscope. A capacitively compensated high voltage probe with a bandwidth up to $75 \mathrm{MHz}$ Tektronix P6015 was used to measure the voltage. An AC/DC Hall current probe with a bandwidth up to $100 \mathrm{MHz}$ Tektronix TCP312 is utilized to measure the current. Instantaneous active power measurements have been evaluated by means of the following expression:

$$
p(t)=v(t) \cdot i(t)
$$

where $v(t)$ and $i(t)$ are the measured voltage and current, $t$ is time. The mean power values reported in this work are obtained by averaging over 25 AC periods. 
Schlieren images have been taken using a Z-type configuration setup as described in [47]. The light beam was along the $z$-direction of Fig. 4. The knife edge was parallel to the actuator surface ( $x$-direction in Fig. 4) so that the Schlieren diagnostic could record density gradients perpendicular to it ( $y$-direction in Fig. 4).

Velocity profiles along the $x$-direction have been measured by means of a glass Pitot tube moved by a step motor with a linear resolution of $0.03 \mathrm{~mm}$. The Pitot tube was connected to a DCAL401 Sursense ultra-low pressure sensor with a sensitivity of $32 \mathrm{mV} / \mathrm{Pa}$ and the measurements have been averaged over 5 different tests [47]. All the measurements have been filtered by using a first order RC low pass filter with a cut off frequency of $100 \mathrm{~Hz}$. Negative pressures detected from the sensor have been set to zero, since only positive pressures can be correlated to air velocities when using a Pitot tube.

ICCD images have been taken using a 4-Picos-dig S20 UV camera equipped with a Nikkor 35-80 f1/4-f1/5.6 lens and an $80 \mu$ s exposure time interval. Separate images of streamers coming from the upper electrode supplied with positive and negative voltages have been taken. In order to do that, the camera has been triggered when the $A C$ voltage crosses the zero with a rising edge (positive voltage streamers) or a falling edge (negative voltage streamers). An $80 \mu s$ exposure time interval has been used. This value ensures only positive or negative voltage streamers are imaged, since the time period of a semi-cycle for the applied 5 $\mathrm{kHz}$ AC voltage is $100 \mu \mathrm{s}$ (Fig.2).

\section{RESULTS AND DISCUSSION}

\section{Electric measurements}

The voltage amplitude and frequency were kept constant at $11.5 \mathrm{kV}_{\mathrm{p}}$ and $5 \mathrm{kHz}$ for all the actuator geometries. In Fig. 5 the average electrical power absorbed by the linear and the annular actuators is plotted. The continuous blue line plot shows the linear actuators, the dashed red one shows the annular actuators. Each of these values refer to the average over 25 time periods of the AC supplied voltage. The standard deviation value observed is limited to $3 \%$. 


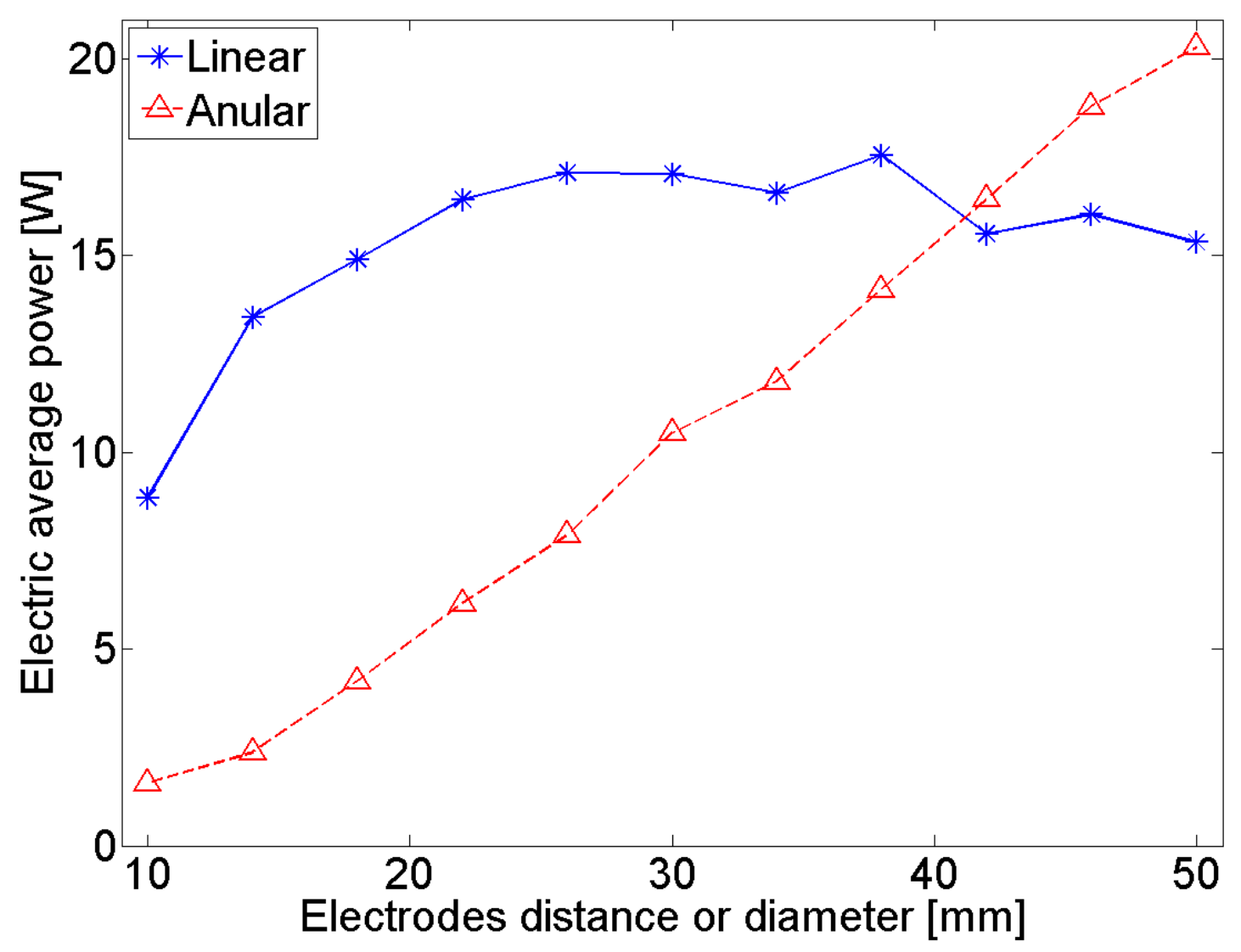

Fig. 5 - Electric power as a function of distances and diameters. The continuous blue line plot shows the linear actuators, the dashed red one shows the annular actuators.

In linear actuators, the electrical power consumption goes from $9 \mathrm{~W}$ with an inter-electrode distance of 10 $\mathrm{mm}$ up to $17 \mathrm{~W}$ at a distance of $26 \mathrm{~mm}$. With larger distances the electrical power remains almost constant at this last value. With annular actuators the electric power increases by increasing the electrode diameter. In fact, the plasma surface linearly grows with increasing diameters. This is due to the geometry of the actuator.

In order to further investigate the nature of those power trends, separate images of streamers coming from the upper electrode supplied with positive and negative voltages have been taken. Figure 6 shows the plasma produced on annular and linear actuators, with an inter-electrode gap of 10 and $26 \mathrm{~mm}$. The upper part of the images show plasma streamers generated from a positive voltage ( $A$ in Fig.2). The lower part of the images show streamers generated from a negative voltage ( $B$ in Fig.2). It is well known from the literature [49] that AC driven DBD actuators streamers are longer, brighter and more spatially separated during positive voltage slopes, while more diffused and limited during the negative ones. 


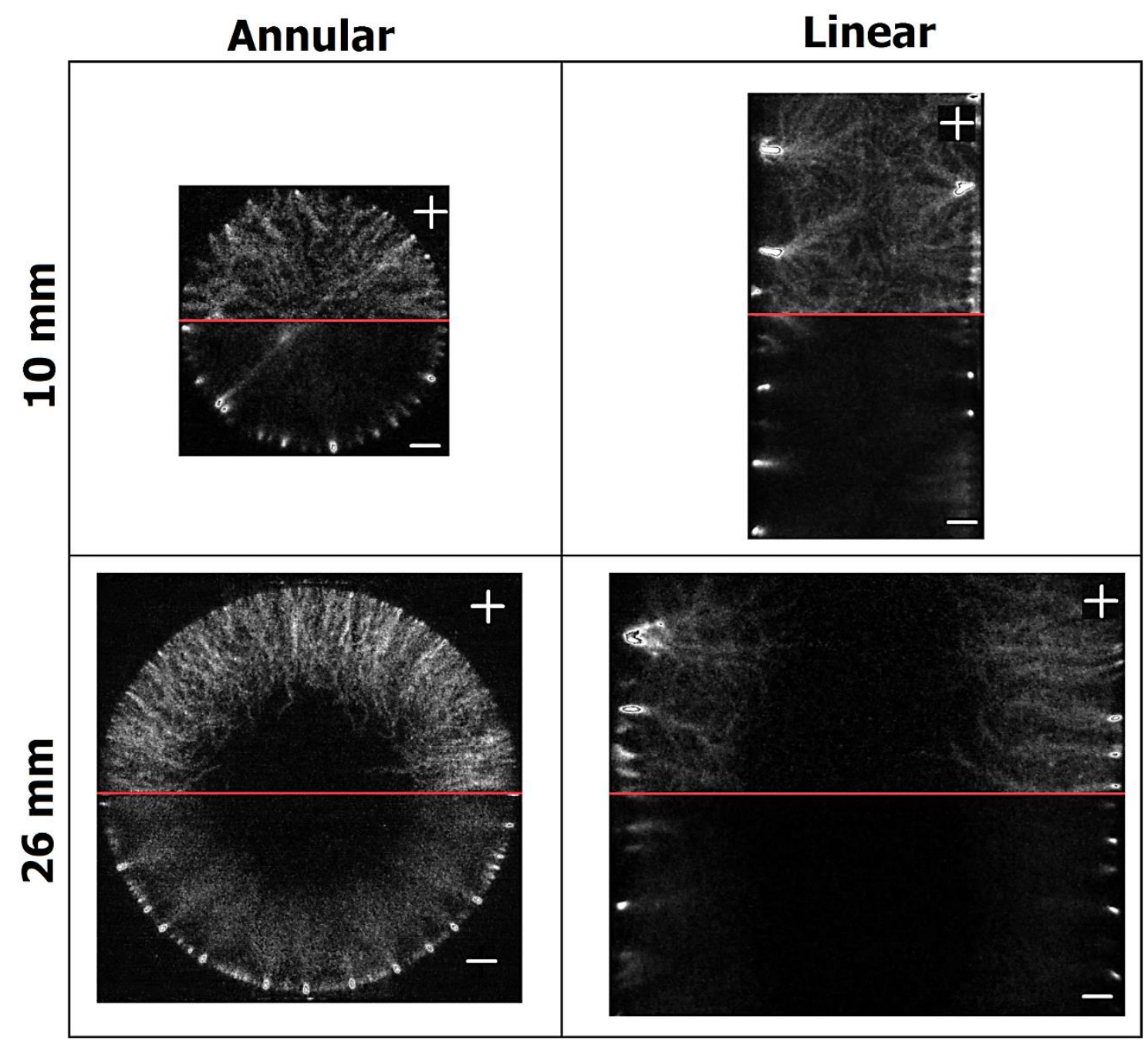

Fig. 6 - ICCD imaging of annular (left column) and linear (right column) actuators, with gaps between the upper electrodes of $10 \mathrm{~mm}$ (first row) and $26 \mathrm{~mm}$ (second row). Each image shows both positive (+ sign at the figure top) and negative (- sign at the figure bottom) streamers.

For the $10 \mathrm{~mm}$ gaps, in both the annular and the linear case, it appears that streamers are completely covering the inter-electrode area. With a gap of $26 \mathrm{~mm}$, streamers are covering only a part of the interelectrode surface in both cases.

The average length in $\mathrm{x}$-direction crossed by a streamer and the dielectric surface covered by plasma has been then determined from the ICCD plasma images. In Fig. 7 these quantities are plotted as functions of the actuator gap (distance of the upper electrodes in the linear actuator and inner diameter in the annular actuator). 
a)

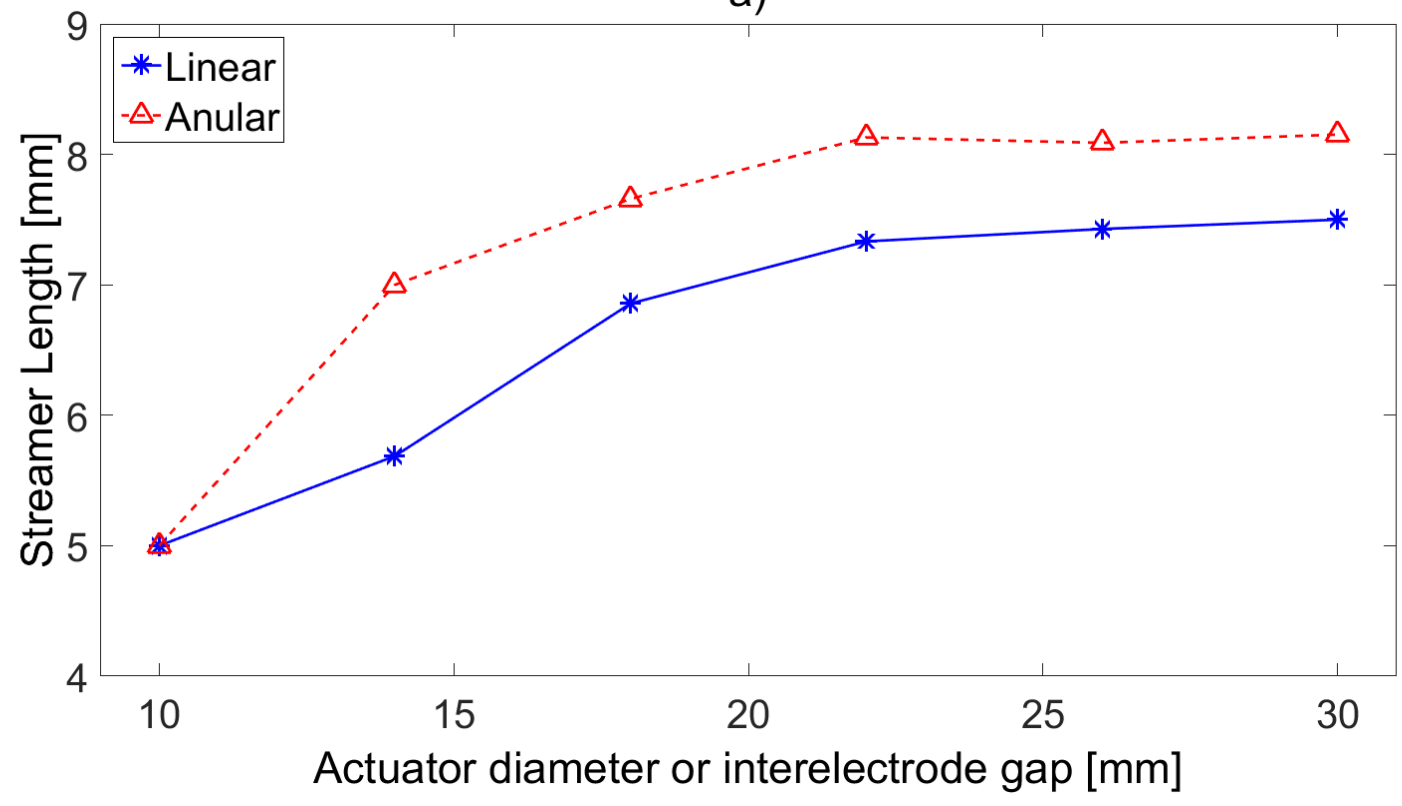

b)

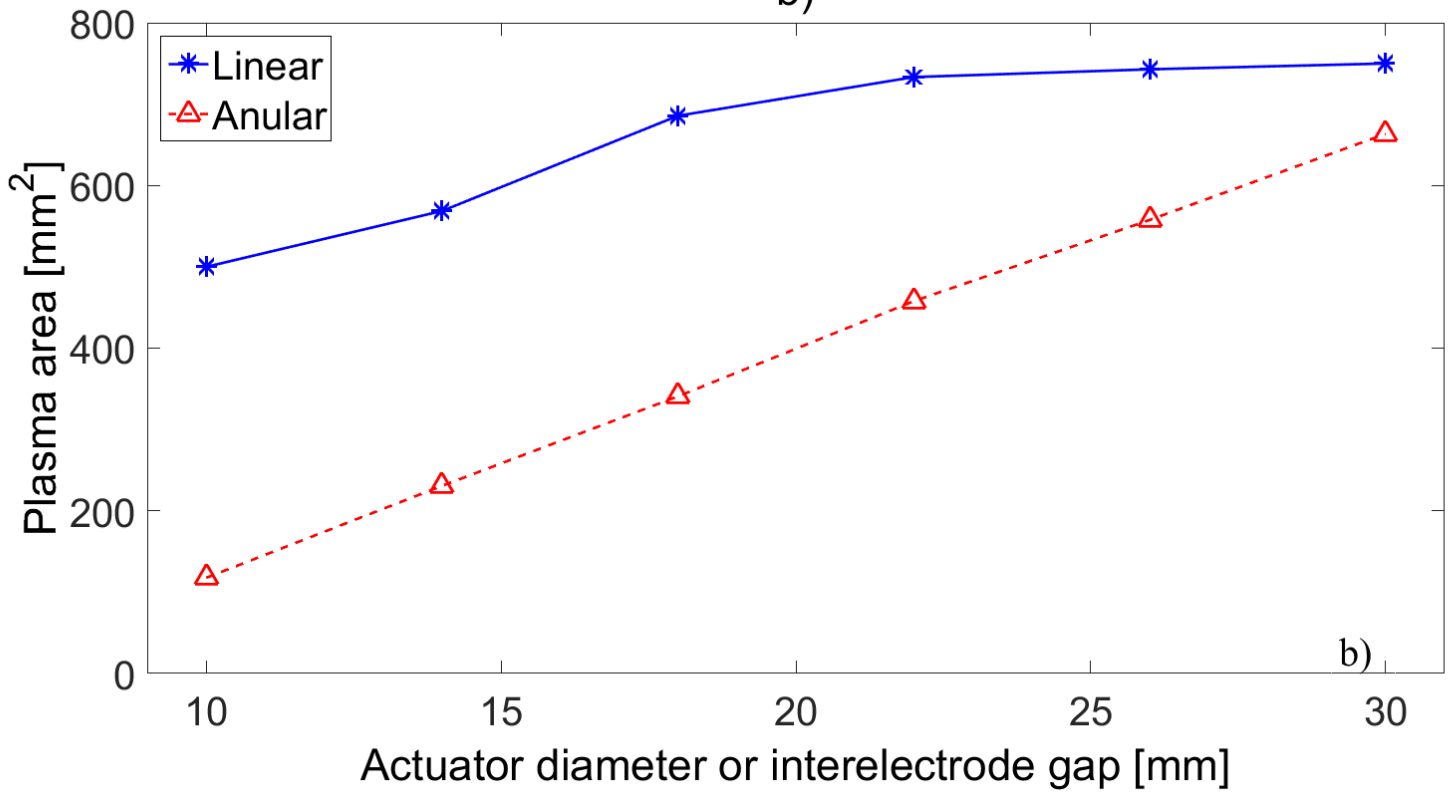

Fig. 7 - (A) Streamer length in annular actuators (blue, continuous line) and in linear actuators (red, dashed line) as a function of the inter-electrode gap and (B) dielectric surface covered by plasma in annular actuators (blue, continuous line) and in linear actuators (red, dashed line) as a function of the interelectrode gap.

Fig. 7 shows how in linear actuators the streamer length is increasing for growing gaps from 10 to $22 \mathrm{~mm}$. With gaps larger than $22 \mathrm{~mm}$, the streamer length remains about equal to $7.4 \mathrm{~mm}$. Correspondingly, the plasma surface goes from $500 \mathrm{~mm}^{2}$ to about $740 \mathrm{~mm}^{2}$. With larger gaps (corresponding to a constant streamer length), plasma surface remains about equal to $740 \mathrm{~mm}^{2}$.

We can deduce that when the streamer is free to completely develop from an upper electrode along the $x$ direction, it crosses a distance of about $7.4 \mathrm{~mm}$; this is what happens for gaps larger than $22 \mathrm{~mm}$. For shorter gaps, the length travelled is smaller, as another streamer is coming from the opposite upper 
electrode. Streamers heads are characterized by a high charged particle density with the same polarity. Two streamers coming from opposite electrodes will therefore tend to repel each other, limiting their development and reducing the distance they can cover.

Such behaviour explains the linear actuators electric power plot we've described in Fig.5. The electrical power increases when the streamer length and the plasma surface increase. For electrode gaps larger than $26 \mathrm{~mm}$, the streamers length and therefore the plasma surface and electrical power, remain constant.

For the annular actuators, when the streamer length is considered, a behaviour similar to the one seen with the linear actuators is observed. However, the plasma surface has an almost linear dependence to the electrode inner diameter, due the azimuthal symmetry of the electrode. We can again correlate the plasma surface area to the electrical power feeding the annular actuators, completely justifying the results described in Fig.5.

\section{Jet Velocity and mechanical efficiency}

Normal component ( $y$-direction) of the induced velocity has been measured by using a Pitot tube positioned at a distance of $5 \mathrm{~mm}$ from actuator surface and moved parallel to it (x-direction). All velocity measurements reported in this work were characterized by relative standard deviations within $10 \%$. This will provide the flow velocities map in the jet's cross-section, $5 \mathrm{~mm}$ above the actuator.

In linear actuators, the jet develops with an elongated shape on the z-y plane. For a long enough actuator, the velocity measured at the same $x$ coordinate and at different $z$ coordinates will result to be the same. In annular actuators, the jet is axisymmetric along the $y$-axis. Given a constant $x$ coordinate, the velocity will be constant for different values of the azimuthal coordinate $\varphi$. Scanning each actuator along the $x$ direction will therefore give us a complete picture of the velocities found in the entire jets.

Figure 8 shows the velocity profiles of linear actuators for different inter-electrode gaps. By increasing the inter-electrode distances, a larger width of the profile in $\mathrm{x}$-direction is observed. For gaps larger than 26 $\mathrm{mm}$ the profile dimension remains nearly unchanged. However, with bigger gaps, the maximum value of the velocity decreases. 


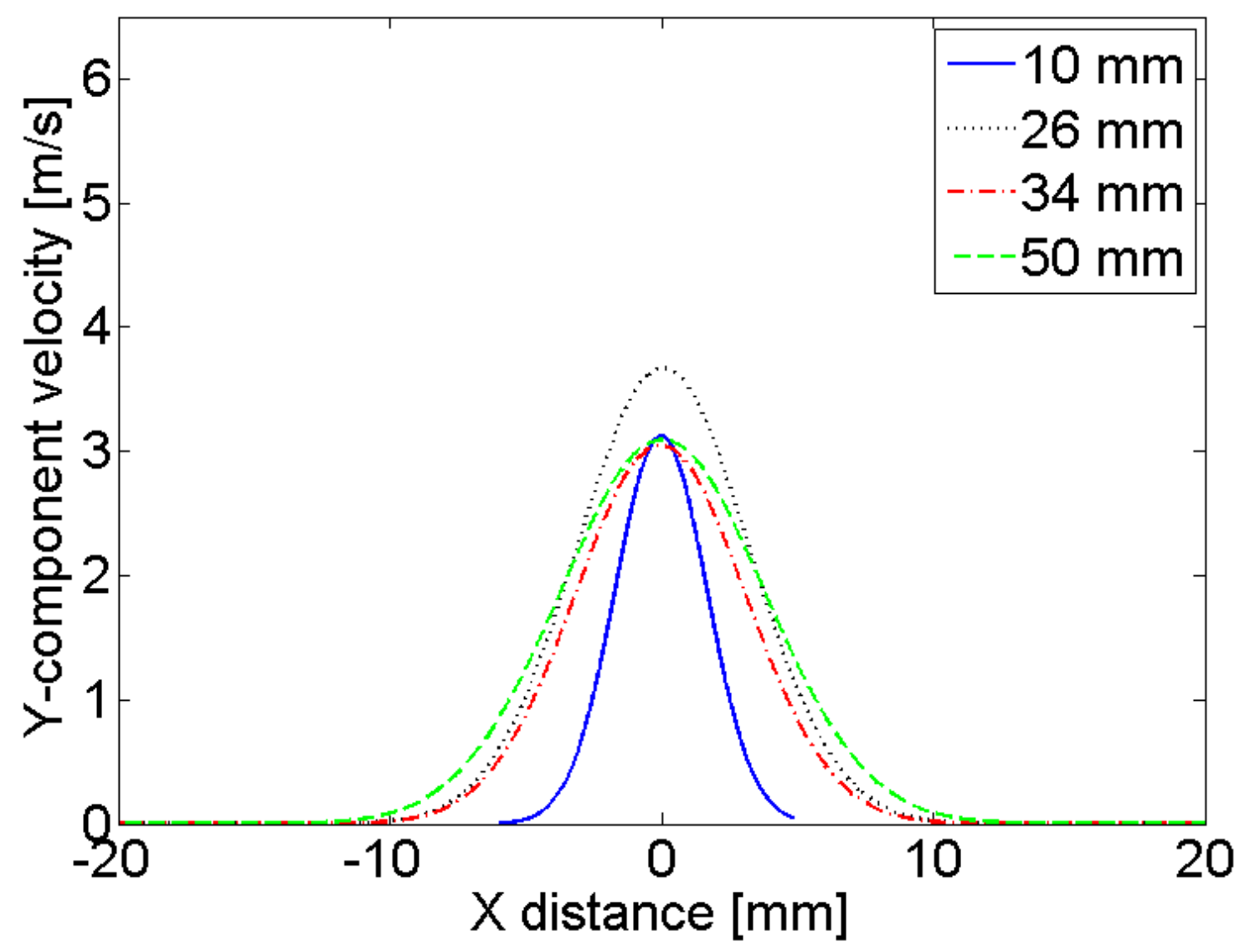

Fig. 8 - Linear actuators velocity profiles at a $5 \mathrm{~mm}$ height above the dielectric surface.

Fig. 9 shows the velocity profiles of the annular actuators at a $5 \mathrm{~mm}$ height above the dielectric surface. In this case, broader profiles have always been measured for increasing diameters. 


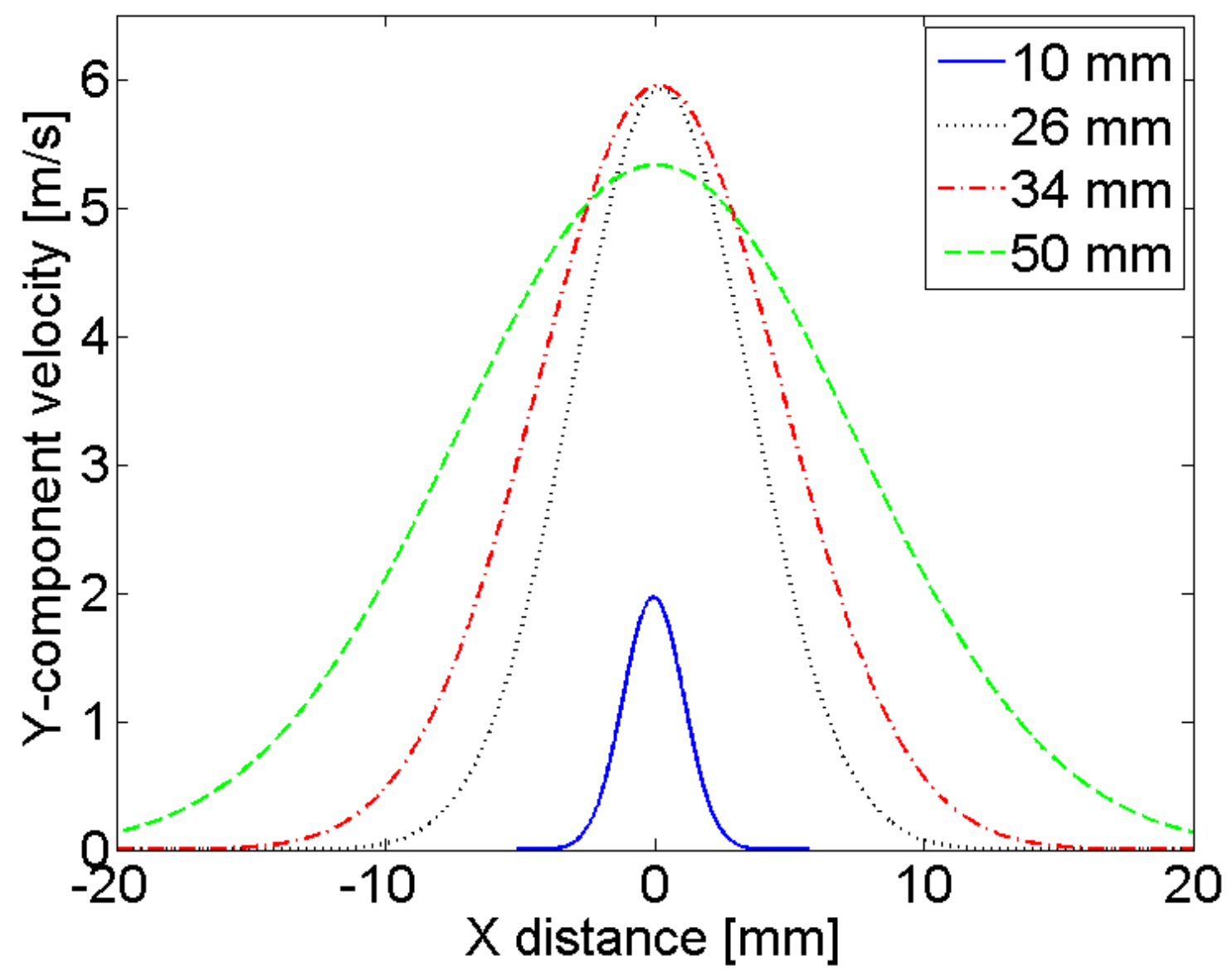

Fig. 9 - Annular actuators velocity profiles at a $5 \mathrm{~mm}$ height above the dielectric surface.

Maximum velocities achieved at a height of $5 \mathrm{~mm}$ above the actuators in the linear and the annular cases are shown in Fig. 10. In the annular actuator the maximum velocity is observed at the centre of the annular actuator, where the $\mathrm{x}=0$ coordinate has been imposed. The maximum velocity increases with larger inner diameters of the upper electrode, until a diameter of $30 \mathrm{~mm}$ is reached. With this diameter the maximum velocity measured at $5 \mathrm{~mm}$ above the actuator surface is $6.1 \mathrm{~m} / \mathrm{s}$. For diameters larger than $30 \mathrm{~mm}$, maximum velocities are decreasing. In the linear actuator the maximum velocity is reached at the centre of the inter-electrode gap, where the coordinate $x=0$ has been imposed. Their plot confirms the same trend discussed in the annular case. With this geometry, the highest value of the maximum velocity is $3.9 \mathrm{~m} / \mathrm{s}$, and it is reached by an electrode gap between 14 and $18 \mathrm{~mm}$. 


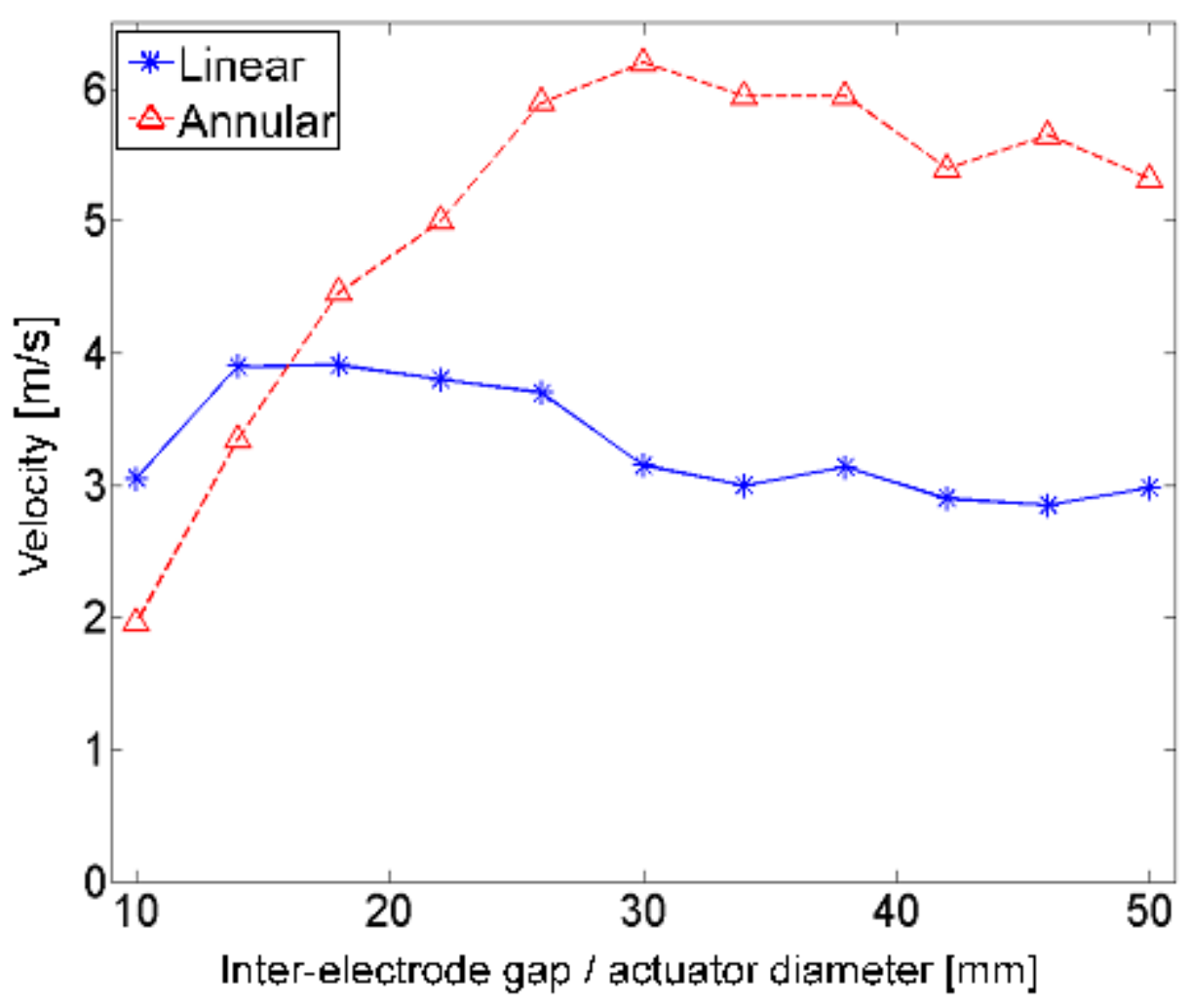

Fig. 10 - Maximum velocity measured at a distance of $5 \mathrm{~mm}$ upon the dielectric surface for different electrode distances and diameters.

The actuators efficiency is defined as the ratio between mechanical and electrical power. The mechanical power for the linear actuator $\mathrm{P}_{\mathrm{m}, \mathrm{L}}$ is derived from the kinetic energy of the jet. It was calculated from the measured velocity profiles, by means of the following expression [50]:

$$
P_{m, L}=\frac{1}{2} \rho L \int_{a}^{b} u^{3}(x) d x
$$

Similarly, mechanical power for the annular actuators, $P_{m, A}$, is defined by:

$$
P_{m, A}=\frac{1}{2} \rho \pi \int_{a}^{b} x u^{3}(x) d x
$$

In both expressions, $\rho$ is atmospheric pressure air density, $L$ is the electrode length in the $z$-direction (50 $\mathrm{mm})$, $\mathrm{a}$ and $\mathrm{b}$ correspond to the edges of the gap on the $\mathrm{x}$-direction, and $u(x)$ is the velocity profile. 


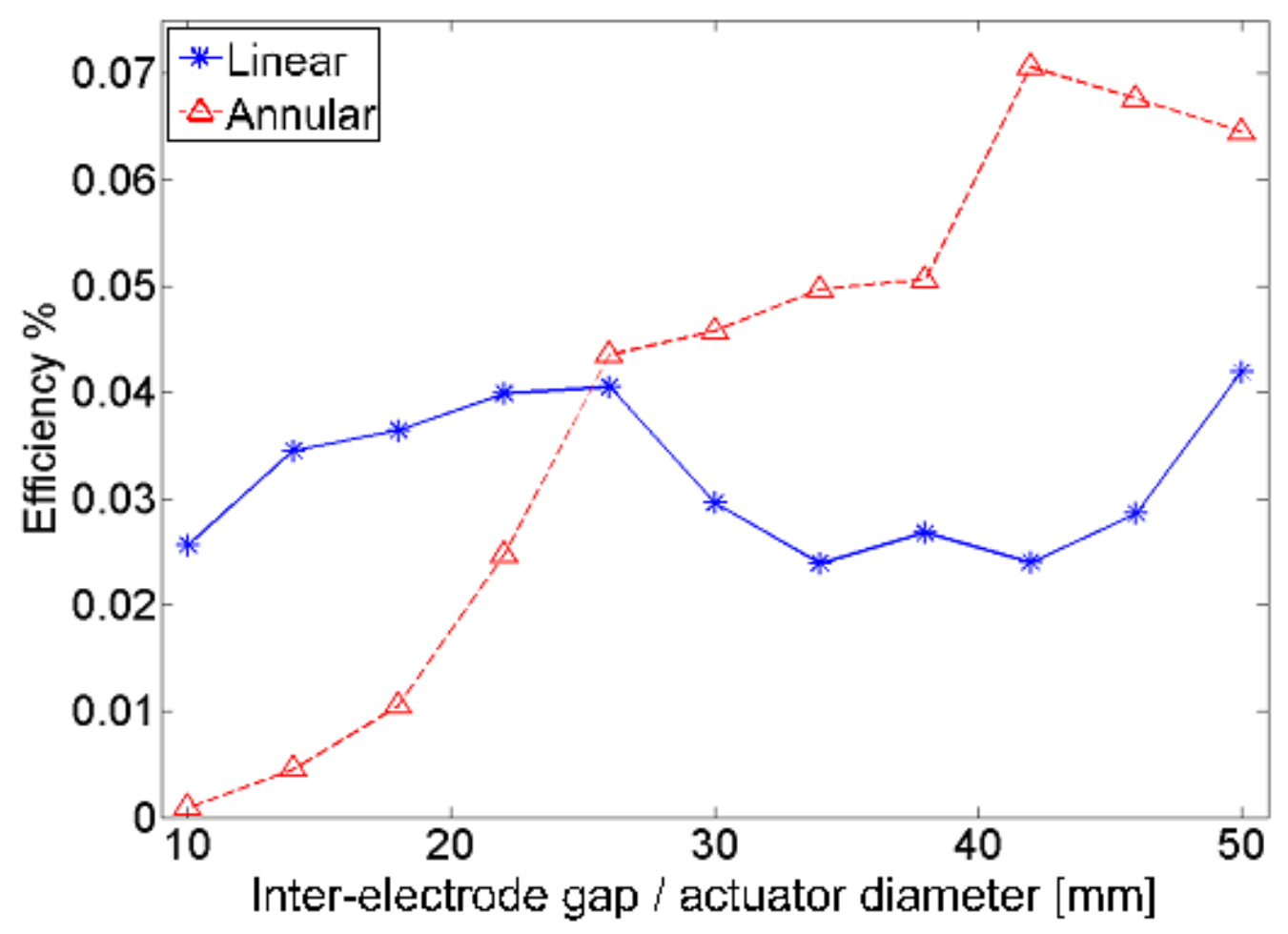

Fig. 11 - Efficiency of the actuator with linear and annular electrodes for different electrode gaps and diameters. The continuous blue plot refers to the linear actuator. The dashed red plot refers to the annular one.

The actuator efficiency is plotted in Fig. 11. The continuous blue plot refers to the linear actuator. The dashed red plot refers to the annular one. Fig.11 shows that the most efficient annular actuator is the one with a $42 \mathrm{~mm}$ diameter. On the other hand, linear actuators don't show a clear trending and we cannot define a single, most efficient geometry. It must be noticed that annular actuators can achieve better efficiencies than the linear ones.

\section{Schlieren Imaging}

In order to visualize the jet during its development, Schlieren images were taken. The CCD camera was triggered with increasing delay times after the discharge ignition, obtaining a complete picture of the jets' development. The exposure time of the camera was set to $1 \mathrm{~ms}$. The validity of this procedure has been checked acquiring several pictures with the same delay and condition, obtaining the same results [47].

Schlieren images of linear and annular jets after $30 \mathrm{~ms}$ from discharge ignition are shown in Fig.12. The jet images confirm the velocity profiles already discussed. After $30 \mathrm{~ms}$ from discharge ignition, the height of the jet of the best performing annular actuator (Fig.12-E) is about $60 \mathrm{~mm}$ and the height of the linear best one is about $42 \mathrm{~mm}$.

Linear jets laminar flow regions are much more limited than the annular counterparts. This effect is supposedly coming from an additional pinching effect annular electrodes produce. While linear actuators are forming a jet on the $y-z$ plane using two streams of ionized air, pushing towards each other on the $x$ axis, the annular ones are producing the same effect on a cylindrical geometry. This in turn generates a 
pinching effect along the $y$-axis that might be the key to the better performances observed with annular electrodes.

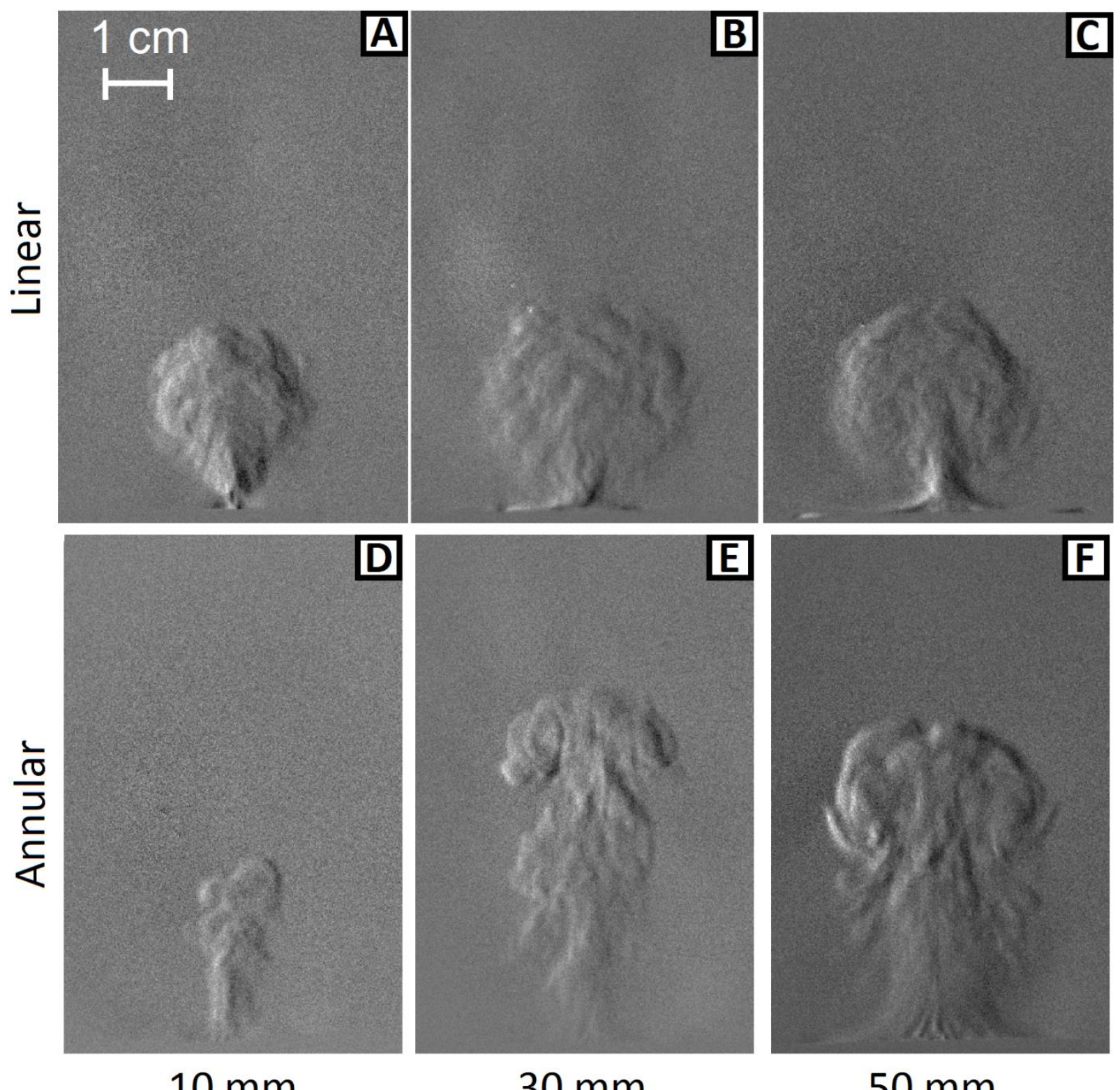

Fig. 12 - Schlieren images of linear jets with a $10 \mathrm{~mm}$ (A), $30 \mathrm{~mm}$ (B) and $50 \mathrm{~mm}$ (C) electrode gap, and annular jets with a $10 \mathrm{~mm}$ (D), $30 \mathrm{~mm}$ (E) and $50 \mathrm{~mm}$ (F) diameter, after $30 \mathrm{~ms}$ from the discharge ignition.

\section{CONCLUSIONS}

Power has been considered the major player when trying to relate plasma parameters with EHD effect. For example, it is well-known that for a given EHD plasma actuator, the velocity of the air jet induced by the DBD discharge increases with the average power until a plateau is reached, and further increases of the average power usually decrease the observed speed[2]. This study shows that geometrical factors are equally important and that at constant input power density different PSJA geometries achieve different performance. 
In the case of annular PSJAs, there is an enhancement given by an axisymmetric pinching effect and their performance in terms of both velocity and conversion efficiency from electrical to kinetic energy can be up to two times in comparison with that of linear actuators.

Therefore, it is concluded that PSJAs geometry is a crucial variable of an EHD plasma actuator. Electrode pattern and inter-electrode distance should be carefully considered in DBD plasma flow control applications. It is not only a simple design choice, but also an effective parameter to be tuned for optimal performance. For the materials and power input levels used in this study, annular electrodes with a $30 \mathrm{~mm}$ diameter outperform other designs. Different boundary conditions are likely to influence the optimal diameter, but annular electrodes seem to be fundamentally better than other geometries.

Mathematical models simulating the chemical yield of reactive species from a surface DBD plasma sometimes do not take into account the convective mechanisms [52-55], but this work shows how important they can actually be. The convective mechanism induced by the air jet is also generating a region with a negative pressure gradient above the exposed electrode. This region will constantly introduce new air into the plasma volume, significantly influencing its chemistry. Another interesting topic would be the influence that an enhanced jet might have for a reactive species delivery to a distant target. This might be of first importance on applications for surface treatments and sterilizations.

\section{REFERENCES}

1. Gad-el-Hak, Mohamed. "Flow control: The future." Journal of Aircraft 38.3 (2001): 402-418.

2. Neretti, Gabriele, et al. "Experimental results in DBD plasma actuators for air flow control." Plasma Science, IEEE Transactions on 40.6 (2012): 1678-1687.

3. Neretti, G., et al. "Recent progress in some aircraft technologies" Department of Mechanical and Aerospace Engineering, Washington University, USA, 2016. ISBN 978-953-51-4658-2

4. Cristofolini, Andrea, Gabriele Neretti, and Carlo Borghi. "Electrohydrodynamic plasma actuator utilizing a dielectric barrier discharge." 38th Fluid Dynamic Conference and Exhibit, Seattle, Washington. 2008.

5. Li, Yong, Xin Zhang, and Xun Huang. "The use of plasma actuators for bluff body broadband noise control." Experiments in fluids 49.2 (2010): 367-377.

6. A. Kurz, S. Grundmann, C. Tropea, M. Forte, A. Seraudie, O. Vermeersch, D. Arnal, N. Goldin, R. King. Boundary layer transition control using DBD plasma actuators. Journal Aerospace Lab. 2013: AL-06-02. ISSN: 2107-6596.

7. Joseph S. Shang, Roger L. Kimmel, James A. Menart, and Sergey T. Surzhikov. "Hypersonic Flow Control Using Surface Plasma Actuator", Journal of Propulsion and Power, Vol. 24, No. 5 (2008), pp. 923-934. http://dx.doi.org/10.2514/1.24413

8. Joseph J. Shang and George Huang. "Modeling surface plasma actuator for flow control", 52nd Aerospace Sciences Meeting, AIAA SciTech, (AIAA 2014-0324) http://dx.doi.org/10.2514/6.2014-0324.

9. I. Maden, R. Maduta, J. Kriegseis, S. Jakirlić, C. Schwarz, S. Grundmann, C. Tropea. Experimental and computational study of the flow induced by a plasma actuator. Active Flow Control by Using Plasma Actuators. International Journal of Heat and Fluid Flow. 2013;41:80-89. DOI: 10.1016/j.ijheatfluidflow.2013.02.013

10. Cristofolini, Andrea, et al. "Study of the Electrical Supply System of a Surface Barrier Discharge for EHD Flow Acceleration." 38th AIAA Plasmadynamics and Lasers Conference. 2007.

11. Huang, Xun, and Xin Zhang. "Plasma actuators for noise control." International Journal of Aeroacoustics 9.4-5 (2010): 679-703.

12. Thomas, Flint O., Alexey Kozlov, and Thomas C. Corke. "Plasma actuators for cylinder flow control and noise reduction." AIAA journal 46.8 (2008): 1921-1931. 
13. A. Cristofolini, C.A. Borghi, and G. Neretti "Charge distribution on the surface of a dielectric barrier discharge actuator for the fluid-dynamic control," Journal of Applied Physics, vol. 113, 143307 (2013), DOI: $10.1063 / 1.4799159$.

14. A. Cristofolini, G. Neretti, and C. A. Borghi, "Effect of the charge surface distribution on the flow field induced by a dielectric barrier discharge actuator," Journal of Applied Physics, vol. 114, 073303, 2013, DOI: $10.1063 / 1.4817378$.

15. Pons, J., E. Moreau, and G. Touchard. "Electrical and aerodynamic characteristics of atmospheric pressure barrier discharges in ambient air."ISNTPT-4. 2004.

16. Corke, T. C., D. A. Cavalieri, and E. Matlis. "Boundary-layer instability on sharp cone at Mach 3.5 with controlled input." AIAA journal 40.5 (2002): 1015-1018.

17. Kelley, Christopher L., et al. "Leading-edge separation control using alternating-current and nanosecond-pulse plasma actuators." AIAA Journal 52.9 (2014): 1871-1884.

18. Opaits, Dmitry F., et al. "Experimental investigation of dielectric barrier discharge plasma actuators driven by repetitive high-voltage nanosecond pulses with dc or low frequency sinusoidal bias." Journal of Applied Physics104.4 (2008): 043304.

19. Arad, B., Y. Gazit, and A. Ludmirsky. "A sliding discharge device for producing cylindrical shock waves." Journal of Physics D: Applied Physics 20.3 (1987): 360.

20. Borghi, C. A., et al. "Electrohydrodynamic interaction induced by a dielectric barrier discharge." Journal of Applied Physics 103.6 (2008): 063304.

21. Junhui Huang, B. E. Separation control over low pressure turbine blades using plasma actuators. Diss. University of Notre Dame, 2005.

22. Nelson, Robert C., et al. "A smart wind turbine blade using distributed plasma actuators for improved performance." Proceedings of the 46th Aerospace Sciences Meeting, Reno, NV, Jan. 2008.

23. Greenblatt, David, Amos Ben-Harav, and Hanns Mueller-Vahl. "Dynamic stall control on a vertical-axis wind turbine using plasma actuators." AIAA journal52.2 (2014): 456-462.

24. Aono, Hikaru, et al. "Plasma flow control simulation of an airfoil of wind turbine at an intermediate Reynolds number." ASME 2013 Fluids Engineering Division Summer Meeting. American Society of Mechanical Engineers, 2013.

25. D. K. Van Ness, II, T. C. Corke, and S. C. Morris, "Tip clearance control using plasma actuators," presented at the 44th AIAA Aerospace Sciences Meeting Exhibit, Reno, NV, Jan. 9-12, 2006, Paper AIAA-2006-21.

26. Amano, Isamu, et al. "Sterilization using a wide-gap discharge formed by dielectric barrier discharge coupled with surface discharge under atmospheric pressure." Industry Applications Conference, 2007. 42nd IAS Annual Meeting. Conference Record of the 2007 IEEE. IEEE, 2007.

27. Martina Fabbri et al., "The effect of plasma surface modification on the biodegradation rate and biocompatibility of a poly(butylene succinate)-based copolymer" Polymer Degradation and Stability 09/2015; 121. DOI:10.1016/j.polymdegradstab.2015.09.015.

28. Moreau, Eric. "Airflow control by non-thermal plasma actuators." Journal of Physics D: Applied Physics 40.3 (2007): 605.

29. Orlov, Dmitri M., Gabriel I. Font, and Daniel Edelstein. "Characterization of discharge modes of plasma actuators." AIAA journal 46.12 (2008): 3142-3148.

30. Enloe, C. L., et al. "Surface potential and longitudinal electric field measurements in the aerodynamic plasma actuator." AIAA journal 46.11 (2008): 2730-2740.

31. Bénard, Nicolas, et al. "Aerodynamic plasma actuators: A directional micro-jet device." Thin Solid Films 516.19 (2008): 6660-6667.

32. Hanson, Ronald E., et al. "Feedback control of slowly-varying transient growth by an array of plasma actuators." Physics of Fluids (1994-present) 26.2 (2014): 024102. 
33. G. Neretti, A. Cristofolini, and C.A. Borghi, "Experimental investigation on a vectorized aerodynamic dielectric barrier discharge plasma actuator array", J. Appl. Physics, vol. 115: 163304, doi: 10.1063/1.4873896, (2014).

34. Borghi, Carlo A., et al. "Wind tunnel experiments on a NACA0015 airfoil equipped with vectorizable dielectric barrier discharge plasma actuators." 32nd AIAA Applied Aerodynamics Conf. paper AIAA 2014-2684, 102514/62014-2684. 2014.

35. He, Chuan, Thomas C. Corke, and Mehul P. Patel. "Plasma flaps and slats: an application of weakly ionized plasma actuators." Journal of Aircraft 46.3 (2009): 864-873.

36. Post, Martiqua L., and Thomas C. Corke. "Separation control on high angle of attack airfoil using plasma actuators." AIAA journal 42.11 (2004): 2177-2184.

37. Lai, Koon Chun. Performance analysis of a dielectric barrier discharge (DBD) plasma actuator. Diss. Universiti Malaysia Sarawak, UNIMAS, 2009.

38. Debien, A., N. BenardP, and E. Moreau. "Single and multi-DBD plasma actuators based on wire HV electrode." 30th ICPIG, August 28th-September 2nd (2011).

39. Riherd, Mark, and Subrata Roy. "Serpentine geometry plasma actuators for flow control." Journal of applied physics 114.8 (2013): 083303.

40. M. Kotsonis, S. Ghaemi. Performance improvement of plasma actuators using asymmetric high voltage waveforms. Journal of Physics D: Applied Physics. 2012;45(045204). DOI: 10.1088/00223727/45/4/045204.

41. Santhanakrishnan, Arvind, and Jamey D. Jacob. "Flow control with plasma synthetic jet actuators." Journal of Physics D: Applied Physics 40.3 (2007): 637.

42. Debien, Antoine, Nicolas Benard, and Eric Moreau. "Streamer inhibition for improving force and electric wind produced by DBD actuators." Journal of Physics D: Applied Physics 45.21 (2012): 215201.

43. Tirumala, Rakshit, et al. "Temperature characterization of dielectric barrier discharge actuators: influence of electrical and geometric parameters." Journal of Physics D: Applied Physics 47.25 (2014): 255203.

44. Borghi, Carlo A., et al. "A plasma aerodynamic actuator supplied by a multilevel generator operating with different voltage waveforms." Plasma Sources Science and Technology 24.4 (2015): 045018.

45. G Correale, T Michelis, D Ragni, M Kotsonis, F Scarano. Nanosecond-pulsed plasma actuation in quiescent air and laminar boundary layer . Journal of Physics D: Applied Physics, 201444 (4), 045204

46. F. A. Dragonas, G. Neretti, P. Sanjeevikumar, G. Grandi, "High-Voltage High-Frequency Arbitrary Waveform Multilevel Generator for DBD Plasma Actuators", IEEE Transactions on Industry Applications, Volume PP, Issue 99, 2015, DOI 10.1109/TIA.2015.2409262.

47. Cristofolini, A., et al. "Schlieren imaging in a dielectric barrier discharge actuator for airflow control." Journal of Applied Physics 111.3 (2012): 033302.

48. Settles, Gary S. Schlieren and shadowgraph techniques: visualizing phenomena in transparent media. Springer Science \& Business Media, 2012.

49. Benard, Nicolas, and Eric Moreau. "Electrical and mechanical characteristics of surface AC dielectric barrier discharge plasma actuators applied to airflow control." Experiments in Fluids 55.11 (2014): 143.

50. J. Kriegseis, A. Duchmann, C.Tropea, and S. Grundmann, "On the classification of dielectric barrier discharge plasma actuators: A comprehensive performance evaluation study", Journal of Physics D: Applied Physics 114, 053301 (2013). doi: 10.1063/1.4817366:

51. Wang, Jin-Jun, et al. "Recent developments in DBD plasma flow control."Progress in Aerospace Sciences 62 (2013): 52-78.

52. Lee, How Ming, Moo Been Chang, and Ta Chin Wei. "Kinetic modeling of ozone generation via dielectric barrier discharges." Ozone: Science and Engineering26.6 (2004): 551-562.

53. Kossyi, I. A., et al. "Kinetic scheme of the non-equilibrium discharge in nitrogen-oxygen mixtures." Plasma Sources Science and Technology 1.3 (1992): 207. 
54. Stefanovic, I., et al. "Kinetics of ozone and nitric oxides in dielectric barrier discharges in O2/NOx and N2/O2/NOx mixtures." Plasma Sources Science and Technology 10.3 (2001): 406.

55. Sakiyama, Yukinori, et al. "Plasma chemistry model of surface microdischarge in humid air and dynamics of reactive neutral species." Journal of Physics D: Applied Physics 45.42 (2012): 425201. 